\title{
KARAKTERISASI SEBARAN CAUCHY
}

\author{
SUSTI RAHMAH YULITA S \\ Program Studi Magister Matematika, \\ Fakultas Matematika dan Ilmu Pengetahuan Alam, Universitas Andalas, \\ Kampus UNAND Limau Manis Padang, Indonesia, \\ sustirahmah@ymail.com
}

\begin{abstract}
Abstrak. Dalam penelitian ini dikaji karakterisasi sebaran Cauchy melalui fungsi karakteristik sebaran dan sebaran terbagi tak hingga. Kehadiran sebaran Cauchy yang dibangkitkan oleh konstanta penstabil menjadi hal yang menarik pula untuk dikaji. Selanjutnya diperoleh eksistensi nilai harapan untuk Sebaran Cauchy yang dibangkitkan oleh konstanta penstabil tersebut. Jika ditentukan suatu sebaran dari suatu peubah acak, maka dapat dikaji bentuk sebaran terbagi tak hingga dari peubah acak tersebut. Oleh karena itu, dalam paper ini akan dikaji pula mengenai sebaran terbagi tak hingga dari sebaran Cauchy dan sebaran Cauchy yang dibangkitkan oleh konstanta penstabil.
\end{abstract}

Kata Kunci: Sebaran Cauchy, sebaran Cauchy dibangkitkan oleh konstanta penstabil, fungsi karakteristik, sebaran terbagi tak hingga

\section{Pendahuluan}

Pada tahun 1853, Augustin Loius Cauchy memperkenalkan sebaran Cauchy yang paling sederhana, yaitu sebaran yang memiliki fungsi kepekatan $f(x)=\frac{1}{\pi\left(1+x^{2}\right)}$, untuk $-\infty<x<\infty$. Einsenhart (1971) memberikan karakterisasi sebaran Cauchy dengan memformulasikan bentuk fungsi karakteristiknya. Setiap fungsi sebaran mempunyai fungsi karakteristik yang merupakan suatu penciri dari suatu sebaran.

Apabila terdapat suatu peubah acak $X_{t}$ yang memiliki sebaran Cauchy $\left(X_{t} \sim\right.$ $C a(a, b))$, dan $S$ didefinisikan oleh $S=\frac{x_{t}}{x^{\prime}}$, di mana $x_{t} \in\left[x_{-r}, x_{q}\right]$, dengan $x^{\prime}=$ $\max \left\{\left|x_{-r}\right|,\left|x_{q}\right|\right\} ; r, q \in \mathbb{Z}$, maka peubah acak $S$ tersebut memiliki fkp

$$
f(S ; a, b)=\frac{b \theta}{\pi\left(b^{2}+(s-a)^{2}\right)},
$$

untuk setiap $-1<s<1$, $a$ dan $b$ masing-masing adalah lokasi dan skala parameter, dan $\theta$ merupakan penstabil bentuk sebaran [7].

Selanjutnya pada tulisan ini akan dikaji tentang karakterisasi sebaran Cauchy dan sebaran Cauchy yang dibangkitkan oleh konstanta penstabil. Karakterisasi yang dikaji meliputi fungsi karakteristik dan sebaran terbagi tak hingga dari masingmasing sebaran.

\section{Peubah Acak dan Fungsi Kompleks}

Suatu peubah acak $X$ dikatakan peubah acak kontinu jika terdapat suatu fungsi $f(x)$ yang dinamakan fkp kontinu sehingga fungsi sebaran dapat dinyatakan sebagai $f(x)=\frac{d}{d x} F(x)$. Misal $X$ adalah peubah acak kontinu dengan fkp $f(x)$, maka 


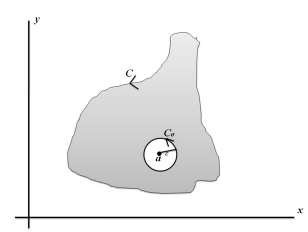

Gambar 2.1. Kurva tertutup terhubung sederhana

nilai harapan dari $X$ didefinisikan oleh $E[X]=\int_{-\infty}^{\infty} x f(x) d x$, jika integral tersebut konvergen mutlak. Selainnya, dikatakan bahwa $E(x)$ tidak ada [1].

Misalkan $f(z)$ terdefinisi dan bernilai tunggal dalam suatu lingkungan dari $z=$ $z_{0}$. Fungsi $f(z)$ dikatakan kontinu di $z=z_{0}$ jika $\lim _{z \rightarrow z_{0}} f(z)=f\left(z_{0}\right)$. Suatu fungsi $f(z)$ dikatakan analitik di suatu titik $z_{0}$ jika terdapat suatu lingkungan $\left|z-z_{0}\right|<\delta$ sehingga $f^{\prime}(z)$ ada di setiap titik pada lingkungan tersebut.

Misalkan $f(z)$ analitik di dalam dan pada suatu kurva tertutup sederhana $C$, dimana $C$ dalam arah positif, dan $a$ adalah suatu titik di dalam $C$, maka

$$
f(a)=\frac{1}{2 \pi i} \oint_{C} \frac{f(z)}{z-a} d z .
$$

Persamaan (2.1) ini dinamakan rumus integral Cauchy.

Fungsi $\frac{f(z)}{z-a}$ analitik di dalam dan pada $C$ kecuali di $z=a$ (Gambar 2.1). Perhatikan bahwa

$$
\oint_{C} \frac{f(z)}{z-a} d z=\oint_{C_{0}} \frac{f(z)}{z-a} d z
$$

di mana $C_{0}$ adalah lingkaran berjari-jari $\varepsilon$. Suatu persamaan untuk $C_{0}$ adalah $|z-a|=\varepsilon$ atau $z-a=\varepsilon e^{i \theta}$ di mana $0 \leq \theta<2 \pi$. Substitusikan $\theta z=a+\varepsilon e^{i \theta}$, $d z=i \varepsilon e^{i \theta}$ maka

$$
\oint_{C_{0}} \frac{f(z)}{z-a} d z=\int_{0}^{2 \pi} \frac{f\left(a+\varepsilon e^{i \theta}\right) i \varepsilon e^{i \theta}}{\varepsilon e^{i \theta}} d \theta=i \int_{0}^{2 \pi} f\left(a+\varepsilon e^{i \theta}\right) d \theta
$$

Sehingga diperoleh $\oint_{C} \frac{f(z)}{z-a} d z=i \int_{0}^{2 \pi} f\left(a+\varepsilon e^{i \theta}\right) d \theta$. Karena $f(z)$ kontinu, maka

$$
\oint_{C} \frac{f(z)}{z-a} d z=\lim _{\varepsilon \rightarrow 0} i \int_{0}^{2 \pi} f\left(a+\varepsilon e^{i \theta}\right) d \theta=i \int_{0}^{2 \pi} \lim _{\varepsilon \rightarrow 0} f\left(a+\varepsilon e^{i \theta}\right) d \theta
$$

Sehingga diperoleh $f(a)=\frac{1}{2 \pi i} \oint_{C} \frac{f(z)}{z-a} d z$

Untuk menentukan fungsi karakteristik untuk sebaran Cauchy, digunakan teorema Residu yang melibatkan fungsi kompleks dalam pembuktiannya. Misalkan $f(z)$ bernilai tunggal dan analitik di dalam dan pada suatu lingkaran $C$, kecuali pada titik $z=a$ yang dipilih sebagai pusat $C$ dengan $z \in \mathbb{C}$. Maka $f(z)$ memiliki uraian Laurent di sekitar $z=a$ yang diberikan oleh

$$
\begin{aligned}
f(z) & =\sum_{n=-\infty}^{\infty} a_{n}(z-a)^{n} \\
& =\cdots+\frac{a_{-2}}{(z-a)^{2}} \frac{a_{-1}}{z-a}+a_{0}+a_{1}(z-a)+a_{2}(z-a)^{2}+.
\end{aligned}
$$


di mana

$$
a_{n}=\frac{1}{2 \pi i} \oint_{C} \frac{f(z)}{(z-a)^{n+1}} d z, n=0, \pm 1, \pm 2, \ldots
$$

Dalam hal khusus $n=-1$ dari persamaan (2.3), diperoleh

$$
\oint_{C} f(z) d z=2 \pi i a_{-1}
$$

Dari kenyataan bahwa persamaan (2.4) hanya melibatkan koefisien $a_{-1}$ dalam persamaan (2.2), maka $a_{-1}$ dinamakan residu dari fungsi $f(z)$ di $z=a$.[10]

Misalkan $C$ adalah suatu kurva tertutup sederhana yang memiliki arah positif. Jika $f$ suatu fungsi bernilai tunggal dan analitik di dalam dan pada $C$ kecuali pada titik-titik kesingularan $z_{k}(k=1,2, \ldots, n)$ di dalam $\mathrm{C}$, maka $\oint_{C} f(z) d z=$ $2 \pi i \sum_{k=1}^{n} \operatorname{Res}_{z=z_{k}} f(z) \cdot[\mathbf{4}]$

\section{Karakterisasi Sebaran}

\subsection{Karakterisasi Sebaran Cauchy}

Misalkan $X$ adalah peubah acak yang memiliki sebaran Cauchy $(X \sim C a(a, b))$, dengan fungsi kepekatan peluang sebagai berikut:

$$
f(x)=\frac{b}{\pi\left(b^{2}+(x-a)^{2}\right)}, \quad-\infty<a<\infty, \quad b>0
$$

untuk setiap $-\infty<x<\infty$. Sebaran Cauchy merupakan sebaran peluang kontinu yang tidak memiliki nilai harapan.

Teorema 3.1. Fungsi karakteristik dari peubah acak $X$ yang menyebar secara Cauchy $(X \sim C a(a, b))$, dinotasikan dengan $\varphi_{X}(t)$, adalah $e^{i a t} e^{-b|t|}$.

Bukti. Langkah 1. Untuk $a=0, b=1$, dan $t>0$.

Perhatikan bahwa

$$
\oint_{C_{n}} \frac{e^{i t z}}{1+z^{2}} d z=2 \pi i
$$

Fungsi $f: z \longmapsto \frac{e^{i t z}}{1+z^{2}}$ memiliki interior region dari $C_{n}$ tepat satu kutub dengan titik $z=i$. Perhatikan bahwa

$$
\frac{e^{i t z}}{1+z^{2}}=\frac{e^{i t z}}{(z-i)(z+i)}
$$

Residu untuk $z=i$ diberikan oleh

$$
\operatorname{Res}_{z=i}\left(\frac{e^{i t z}}{1+z^{2}}\right)=\lim _{z \rightarrow i}(z-i) f(z)=\frac{e^{-t}}{2 i}
$$

Oleh karena itu,

$$
\oint_{C_{n}} \frac{e^{i t z}}{1+z^{2}} d z=2 \pi i \operatorname{Res}_{z=i}\left(\frac{e^{i t z}}{1+z^{2}}\right)=\pi e^{-t}, \quad n>2
$$




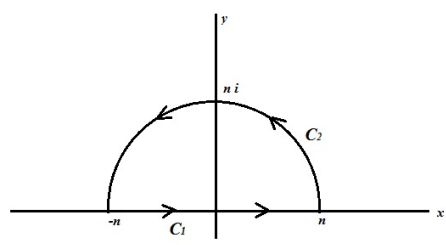

Gambar 3.1. Contour 1

Pengintegralan sepanjang contour $C_{n}$ dapat diperoleh sebagai berikut

$$
\begin{aligned}
\pi e^{-t} & =\oint_{C_{n}} \frac{e^{i t z}}{1+z^{2}} d z \\
\pi e^{-t} & =\int_{-n}^{n} \frac{e^{i t x}}{1+x^{2}} d x+\int_{0}^{\pi} \frac{e^{i t n e^{i \beta}}}{1+n^{2} e^{2 i \beta}} n i e^{i \beta} d \beta
\end{aligned}
$$

Hasil pengintegralan suku kedua pada sisi kanan konvergen ke nol jika $n \rightarrow \infty$. Perhatikan bahwa $\left|n^{2} e^{2 i \beta}+1\right| \geq n^{2}-1$. Maka

$$
\left|\frac{e^{i t n e^{i \beta}}}{1+n^{2} e^{2 i \beta}} n i e^{i \beta}\right| \leq \frac{n e^{-n t \sin \beta}}{n^{2}-1} \leq \frac{n}{n^{2}-1} .
$$

Karena

$$
\left|\int_{0}^{\pi} \frac{e^{i t n e^{i \beta}}}{1+n^{2} e^{2 i \beta}} n i e^{i \beta} d \beta\right| \leq \int_{0}^{\pi}\left|\frac{e^{i t n e^{i \beta}}}{1+n^{2} e^{2 i \beta}} n i e^{i \beta}\right| d \beta \leq \int_{0}^{\pi} \frac{n}{n^{2}-1} d \beta=\frac{2 \pi n}{n^{2}-1},
$$

maka

$$
\lim _{n \rightarrow \infty} \int_{0}^{\pi} \frac{e^{i t n e^{i \beta}}}{1+n^{2} e^{2 i \beta}} n i e^{i \beta} d \beta=0 .
$$

Untuk $n \rightarrow \infty$ pada persamaan (3.2), diperoleh

$$
\int_{-\infty}^{\infty} \frac{e^{i t x}}{1+x^{2}} d x=\pi e^{-t}
$$

Langkah 2. Untuk $a=0, b=1$, dan $t<0$.

Dengan mengikuti Langkah 1 diperoleh

$$
\int_{-\infty}^{\infty} \frac{e^{i t x}}{1+x^{2}} d x=\pi e^{t}
$$

Langkah 3. Untuk kasus umum

Berdasarkan Langkah 1 dan Langkah 2, maka

$$
\int_{-\infty}^{\infty} \frac{e^{i t x}}{1+x^{2}} d x=\pi e^{-|t|}
$$

Untuk pengintegralan $\int_{-\infty}^{\infty} \frac{e^{i t x}}{b^{2}+(x-a)^{2}} d x$, terlebih dahulu substitusikan $x=v+a$, sehingga diperoleh

$$
\int_{-\infty}^{\infty} \frac{e^{i t x}}{b^{2}+(x-a)^{2}} d x=e^{i t a} \int_{-\infty}^{\infty} \frac{e^{i t(v)}}{v^{2}+b^{2}} d v
$$


Dengan mensubstitusikan $v=b u$ pada pengintegralan terakhir, diperoleh

$$
\int_{-\infty}^{\infty} \frac{e^{i t x}}{b^{2}+(x-a)^{2}} d x=\frac{\pi}{b} e^{i t a} e^{-b|t|}
$$

Oleh karena itu

$$
\int_{-\infty}^{\infty} \frac{e^{i t x} b}{\pi\left(b^{2}+(x-a)^{2}\right)} d x=\frac{b}{\pi} \int_{-\infty}^{\infty} \frac{e^{i t x}}{b^{2}+(x-a)^{2}} d x=e^{i t a} e^{-b|t|}
$$

Beberapa sifat karakteristik dari sebaran Cauchy adalah sebagai berikut.

(1) Misalkan $\varphi_{X}(t)=e^{i t a} e^{-b|t|}$ adalah fungsi karakteristik dari peubah acak $(X \sim$ $C a(a, b))$, maka $\varphi_{x}(0)=e^{i(0) a} e^{-b|(0)|}=1$.

(2) Misalkan $X$ suatu peubah acak $(X \sim C a(a, b))$, maka fungsi karakteristik dari $-X$ adalah $\overline{\varphi_{X}(t)}$

(3) Fungsi karakteristik $\varphi_{X}(t)=e^{i t a} e^{-b|t|}$ adalah kontinu seragam. Misalkan $\varphi_{X}(t)=e^{i t a} e^{-b|t|}=e^{i t a-b|t|}=\varphi(z(t))$.

Selanjutnya akan diperlihatkan bahwa sebaran Cauchy adalah sebaran terbagi tak hingga. Perhatikan bahwa $X \sim C a(a, b)$, dan $\varphi(t)=e^{i t a} e^{-b|t|}$. Jika dimisalkan $\varphi_{n}(t)=[\varphi(t)]^{\frac{1}{n}}$ maka

$$
\begin{aligned}
\varphi_{n}(t) & =[\varphi(t)]^{\frac{1}{n}} \\
& =\left[e^{i t a-b|t|}\right]^{\frac{1}{n}} \\
& =e^{\frac{i t a}{n}-\frac{b|t|}{n}} \\
& =e^{i t \frac{a}{n}-|t| \frac{b}{n}}
\end{aligned}
$$

Karena fungsi karakteristik dari peubah $X$ yang menyebar secara Cauchy $(a, b)$ dapat dituliskan $\varphi_{n}(t)=[\varphi(t)]^{\frac{1}{n}}$, untuk $n$ adalah bilangan bulat positif, maka $X \sim C a\left(\frac{a}{n}, \frac{b}{n}\right)$ dan sebaran Cauchy dikatakan sebagai sebaran terbagi tak hingga.

\subsection{Karakterisasi Sebaran Cauchy yang dibangkitkan oleh Konstanta Penstabil}

Misalkan $X_{t}$ adalah suatu peubah acak yang memiliki sebaran Cauchy $\left(X_{t} \sim\right.$ $C a(a, b))$, dengan $S$ adalah peubah acak yag didefinisikan sebagai berikut.

$$
S=\frac{x_{t}}{x^{\prime}}
$$

di mana $x_{t} \in\left[x_{-r}, x_{q}\right]$, dengan $x^{\prime}=\max \left\{\left|x_{-r}\right|,\left|x_{q}\right|\right\} ; r, q \in \mathbb{Z}$, maka peubah acak $S$ tersebut memiliki fkp

$$
f(S ; a, b)=\frac{b \theta}{\pi} \frac{1}{b^{2}+(s-a)^{2}},
$$

untuk setiap $-1<s<1, \quad-1<a<1, \quad b>0$,

dengan $\theta$ merupakan penstabil bentuk sebaran yang bergantung pada $a$ dan $b$ yaitu $\theta=\frac{\pi}{2 \tan ^{-1}\left(\frac{1-a}{b}\right)}$ Sehingga fungsi kepekatan peluang $S$ dapat ditulis sebagai

$$
f(S ; a, b)=\frac{1}{2 \tan ^{-1}\left(\frac{1-a}{b}\right)}\left(\frac{b}{b^{2}+(s-a)^{2}}\right) .
$$


untuk setiap $-1<s<1, a<1, b>0$.

Kehadiran dari suatu konstanta penstabil dalam sebaran Cauchy, mengakibatkan nilai harapan dari sebaran Cauchy yang dibangkitkan dengan konstanta penstabil $\left(S \sim C a_{\text {penstabil }}(a, b)\right)$ ada yaitu

$$
\begin{aligned}
E(S)= & \int s f(s) d s \\
= & \frac{1}{2 \tan ^{-1}\left(\frac{1-a}{b}\right)}\left[\frac{1}{2}\left(\log \left(1-2 a+a^{2}+b^{2}\right)\right)-\left(\log \left(1+2 a+a^{2}+b^{2}\right)\right)\right. \\
& \left.+\frac{a}{b}\left(\tan ^{-1}\left(\frac{1-a}{b}\right)\right)+\left(\tan ^{-1}\left(\frac{1+a}{b}\right)\right)\right]
\end{aligned}
$$

Teorema 3.2. Jika $S$ adalah peubah acak memiliki sebaran Cauchy yang dibangkitkan oleh konstanta penstabil $\left(S \sim C a_{\text {penstabil }}(a, b)\right)$ dengan $f k p$

$$
f(S ; a, b)=\frac{1}{2 \tan ^{-1}\left(\frac{1-a}{b}\right)}\left(\frac{b}{b^{2}+(s-a)^{2}}\right) .
$$

untuk setiap $-1<s<1, a<1, b>0$, maka peubah acak tersebut memiliki fungsi karakteristik $\varphi_{S}(t)=\frac{\pi}{2 \tan ^{-1}\left(\frac{1-a}{b}\right)} e^{i a t} e^{-b|t|}=\theta e^{i a t} e^{-b|t|}$.

Bukti. Langkah 1. Untuk $a=0, b=1$, dan $t>0$.

Perhatikan bahwa

$$
\oint_{C_{n}} \frac{e^{i t z}}{1+z^{2}} d z=2 \pi i
$$

Fungsi $f: z \longmapsto \frac{e^{i t z}}{1+z^{2}}$ memiliki interior region dari $C_{n}$ tepat satu kutub dengan titik $z=i$. Perhatikan bahwa

$$
\frac{e^{i t z}}{1+z^{2}}=\frac{e^{i t z}}{(z-i)(z+i)}
$$

Residu untuk $z=i$ diberikan oleh

$$
\operatorname{Res}_{z=i}\left(\frac{e^{i t z}}{1+z^{2}}\right)=\lim _{z \rightarrow i}(z-i) f(z)=\frac{e^{-t}}{2 i}
$$

Oleh karena itu,

$$
\oint_{C_{n}} \frac{e^{i t z}}{1+z^{2}} d z=2 \pi i \operatorname{Res}_{z=i}\left(\frac{e^{i t z}}{1+z^{2}}\right)=\pi e^{-t}, \quad n>2
$$

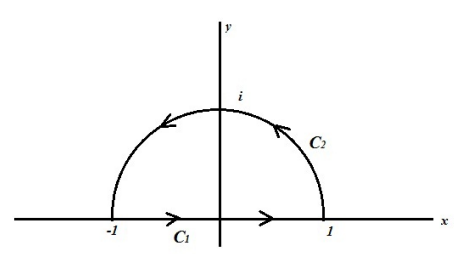

Gambar 3.2. Contour 2 
Pengintegralan sepanjang contour $C_{n}$ dapat diperoleh sebagai berikut

$$
\begin{aligned}
\pi e^{-t} & =\oint_{C_{n}} \frac{e^{i t z}}{1+z^{2}} d z \\
& =\int_{-1}^{1} \frac{e^{i t s}}{1+s^{2}} d s+\int_{0}^{\pi} \frac{e^{i t e^{i \beta}}}{1+e^{2 i \beta}} i e^{i \beta} d \beta
\end{aligned}
$$

Perhatikan bahwa $1+e^{2 i \beta} i e^{i \beta} \geq e^{2 i \beta}$. Maka

$$
\left|\frac{e^{i t e^{i \beta}}}{1+e^{2 i \beta}} i e^{i \beta}\right| \leq \frac{e^{-t \sin \beta}}{e^{2 i \beta}} \leq \frac{1}{e^{2 i \beta}}
$$

dengan demikian

$$
\int_{0}^{\pi} \frac{e^{i t e^{i \beta}}}{1+e^{2 i \beta}} i e^{i \beta} d \beta=0
$$

Sehingga diperoleh

$$
\begin{aligned}
& \int_{-1}^{1} \frac{e^{i t s}}{1+s^{2}} d s=\pi e^{-t} \\
& \int_{-1}^{1} \frac{\theta e^{i t s}}{1+s^{2}} d s=\theta \pi e^{-t}
\end{aligned}
$$

Langkah 2. Untuk $a=0, b=1$, dan $t<0$.

Dengan cara yang sama seperti Langkah 1 diperoleh

$$
\int_{-1}^{1} \frac{\theta e^{i t s}}{1+s^{2}} d s=\theta \pi e^{t}
$$

Langkah 3. Kasus umum.

Berdasarkan Langkah 1 dan Langkah 2, diperoleh bahwa

$$
\int_{-1}^{1} \frac{\theta e^{i t s}}{1+s^{2}} d s=\theta \pi e^{-|t|} .
$$

Untuk pengintegralan

$$
\int_{-1}^{1} \frac{\theta e^{i t s}}{b^{2}+(s-a)^{2}} d s,
$$

terlebih dahulu substitusikan $s=v+a$, sehingga diperoleh

$$
\int_{-1}^{1} \frac{\theta e^{i t s}}{b^{2}+(s-a)^{2}} d s=\theta e^{i t a} \int_{-1}^{1} \frac{e^{i t(v)}}{v^{2}+b^{2}} d v
$$

Dengan mensubstitusikan $v=b u$ pada pengintegralan terakhir diperoleh

$$
\int_{-1}^{1} \frac{\theta e^{i t s}}{b^{2}+(s-a)^{2}} d s=\frac{\theta \pi}{b} e^{i t a} e^{-b|t|}
$$

Oleh karena itu

$$
\int_{-1}^{1} \frac{\theta e^{i t s} b}{\pi\left(b^{2}+(s-a)^{2}\right)} d s=\theta e^{i t a} e^{-b|t|}
$$


Dengan demikian, diperoleh fungsi karakteristik dari sebaran Cauchy yang dibangkitkan dengan konstanta penstabil $\left(S \sim C a_{\text {penstabil }}(a, b)\right)$ adalah $\varphi_{S}(t)=\theta e^{i t a} e^{-b \mid t}$

Berikut adalah beberapa sifat fungsi karakteristik dari peubah acak $S$ yang menyebar secara Cauchy dengan konstanta penstabil $\left(S \sim C a_{\text {Penstabil }}(a, b)\right)$.

(1) Misalkan $S$ suatu peubah acak $\left(S \sim C a_{\text {Penstabil }}(a, b)\right)$, maka fungsi karakteristik dari $-S$ adalah $\overline{\varphi_{S}(t)}$

(2) Peubah acak $X$ mempunyai sebaran Cauchy dengan fkp

$$
f(x)=\frac{\theta b}{\pi\left(b^{2}+(x-a)^{2}\right)} .
$$

Misalkan $Y=-X$, maka diperoleh Jakobian $J=\left|\frac{d S}{d Y}\right|=1$. Untuk peubah acak $Y$ maka fkp peubah acak tersebut adalah $f(-s)=f_{S, Y}(-s)|J|=\frac{\theta b}{\pi\left(b^{2}+(x+a)^{2}\right)}$

(3) Fungsi karakteristik $\varphi_{S}(t)=\theta e^{i t a} e^{-b|t|}$ adalah kontinu seragam.

(4) Misalkan $S$ adalah suatu peubah acak dengan sebaran Cauchy yang dibangkitkan oleh konstanta penstabil $(S \sim C a(a, b))$, maka fungsi karakteristik dari $\alpha+\beta S$ adalah $e^{i t S} \varphi_{S}(\beta t)$

Perhatikan bahwa $S \sim C a_{P e n s t a b i l}(a, b)$, dan $\varphi(t)=\theta e^{i t a} e^{-b|t|}$. Jika dimisalkan $\varphi_{n}(t)=[\varphi(t)]^{\frac{1}{n}}$ maka

$$
\begin{aligned}
\varphi_{n}(t) & =[\varphi(t)]^{\frac{1}{n}} \\
& =\left[\theta e^{i t a-b|t|}\right]^{\frac{1}{n}} \\
& =\theta^{\frac{1}{n}} e^{i t \frac{a}{n}-|t| \frac{b}{n}}
\end{aligned}
$$

Karena fungsi karakteristik dari peubah $S$ menyebar secara Cauchy, yang dibangkitkan oleh konstanta penstabil $C a \sim(a, b)$, dapat dituliskan sebagai $\varphi_{n}(t)=[\varphi(t)]^{\frac{1}{n}}$, untuk bilangan bulat positif $n$, maka $S \sim C a_{P e n s t a b i l}\left(\frac{a}{n}, \frac{b}{n}\right)$ dan sebaran Cauchy yang dibangkitkan oleh konstanta penstabil $S \sim C a_{\text {Penstabil }}(a, b)$ dikatakan sebagai sebaran terbagi tak hingga.

\section{Ucapan Terima kasih}

Penulis mengucapkan terima kasih kepada Bapak Dr. Dodi Devianto, Bapak Dr. Admi Nazra, Bapak Dr. Muhafzan, Ibu Dr. Maiyastri, Ibu Dr. Lyra Yulianti, dan Ibu Dr. Ferra Yanuar yang telah memberikan masukan dan saran sehingga paper ini dapat diselesaikan dengan baik.

\section{Daftar Pustaka}

[1] Bain, Lee J and Max. E. 1992. Introduction to Probability and Mathematical Statistics, Second Edition . Duxbury Press, California.

[2] Bartle, R.G. dan Donald R.S. 1927. Introduction to Real Analysis Second Edition. John Wiley and Sons, Inc., Singapore.

[3] Casella, G. dan Berger, Roger L. 1990. Statistical Inference. Pasific Grove, California. 
[4] Churchill, Ruel V. dan James Ward Brown. 1996. Complex Variables and Applications, Sixth Edition. McGraw-Hill, Inc, Singapore.

[5] Laha, R. G. dan V. K. Rohatgi. 1979. Probability Theory. John Wiley dan Sons, New York

[6] Lukacs, Eugene. 1970. Characteristic Function. Edisi Ke-2. Butler dan Tanner, London.

[7] Osu, Bright O., dan Johnson Ohakwe. 2011. Financial Risk Assesment with Cauchy Distribution under a Simple Transformation of Dividing with a Constant. Theoretical Mathematics and Applications, Vol.1, No.1. International Scientific Press.

[8] Purcel, E.J., D. Varberg. dan S.E. Rigdon. 2004. Kalkulus dan Geometri Analitis Jilid I, Ahli Bahasa I Nyoman Susila Edisi ke-8 . Erlangga, Jakarta.

[9] Rao, M.M dan Randall J. Swift. 2006. Probability with Applications Second Edition. Springer, UniteD States of America.

[10] Spiegel, Murray R. 1987. Peubah Kompleks, Ahli Bahasa Koko Martono. Erlangga, Jakarta.

[11] Tucker, H. G. 1967. Probability and Mathematical Statistics. Academic Press, London. 